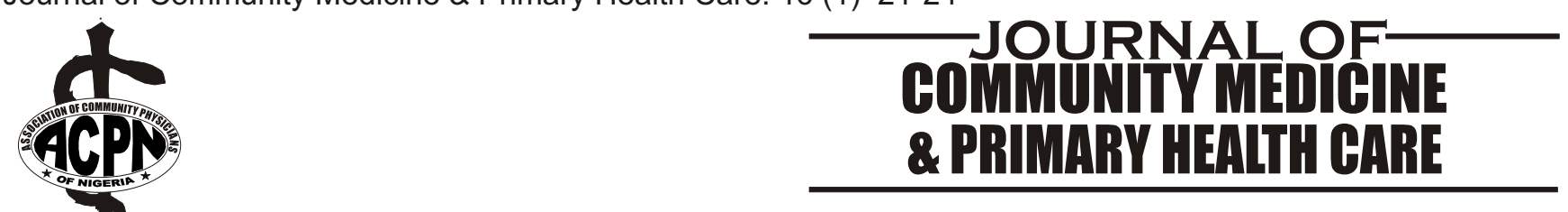

\title{
Drug use indicators at a secondary health care facility in Lagos, Nigeria.
}

\subsection{Odusanya}

\author{
Department of Community Health \& Primary Health Care \\ Lagos State University College of Medicine \\ P.M.B. 21266, Ikeja
}

\section{KEY WORDS: \\ Drug-use, \\ Indicators \\ Secondary \\ health \\ facilities, \\ Lagos}

\section{Abstract}

Objective: Drug-use indicators were measured in a secondary health care facility in Lagos, Nigeria

Method: Retrospective prescribing data was used and patient records were selected using a systematic sampling method.

Results:The average number of drugs per patient was $3.5=1=1.4,14 \%$ of patients received at least one injection and $55 \%$ of patients were prescribed at least one antibiotic. The injections were prescribed for a variety of indications where oral therapy could have been used. Antibiotics were prescribed largely for presumed infections.

Conclusion: These indicators show that the level of drug use at the hospital is sub-optimal and need to be improved upon.

\section{Introduction}

Drugs play an important role in the health care delivery system, giving it credibility. Availability of drugs is one factor known to improve utilization of health services. ${ }^{1}$ Drugs are expensive, constitute a large percentage of the costs of health care and therefore require optimal or rational use. Rational drug use refers to the prescribing of the right drug for the right indication in the right dosage and dosing frequency for the correct duration. ${ }^{2}$ Drug use indicators are a set of standardized indices used to measure drug use in outpatient facilities., ${ }^{3,4}$ They provide a measure of the optimal use of these resources and can help in correcting deviations from expected standards and in planning.

Drug use indicators include average number of drugs per patient encounter, percentage of patient encounters with a prescribed injection, percentage of patient encounters with a prescribed antibiotic to mention a few. Drug use indicators in Nigeria show very high levels and often reflect irrational drug use ${ }^{5-8}$ .The average numbers of drugs prescribed per patient had been found to vary from 3 to 7 , the prescribing rate of injection has a range of $40-70 \%$ and antibiotic use rate exceeds $50 \%$.

Much of the available information on drug use

Correspondence to: Dr. 0.0. Odusanya,

Dept of Community Health \& Primary Health Care

Lagos State University College of Medicine

P.M.B. 21266, Ikeja indicators have either come from the tertiary facilities ${ }^{5}$ or the primary care level ${ }^{8}$ mainly due to research activities undertaken by university staff. There is paucity of drug use data from secondary health care level, which also serve a large percentage of the population, as only few studies have been conducted at this level. This study investigates drug use indicators at a secondary health care facility at the Ikeja General Hospital, Lagos

\section{Methods}

\section{Background}

The study was conducted in the year 2000 at the Ikeja General Hospital, Lagos, Nigeria. The hospital was at this period being upgraded to a university teaching hospital consequent to the establishment of the Lagos State University College of Medicine. The hospital serves the population of Ikeja local government and other adjoining areas.

\section{Study Design}

Standardised methods of investigating drug use indicators were employed in the conduct of the study. ${ }^{4}$ These methods recommend a study of 100 patient records in a single health facility or 30 records in 10 different clinics/ health facilities. The study was planned to investigate 600 patient records to increase the precision of the parameters. The records studied were for patients attended to at the outpatient department of the hospital in the first three months of the year 2000. 
Patient records from the outpatient clinics of both adult and paediatric departments of the hospital were obtained. The attendance record during the period showed that the ratio of adult-to-paediatric attendance was $2: 1$. This ratio was used to plan to select 400 adult records and 200 paediatric records. The records were selected using a systematic sampling method with a sampling fraction of 1:20 for the adults and 1:15 for the paediatric records.

Table 1. Drug Use Indicators
\begin{tabular}{lll}
\hline Indicators & $\mathrm{N}$ & $\%$ \\
\hline & & \\
Average number of drugs per encounter & $3.5(1.4)$ & 54.8 \\
Mean(SD) & $279 / 509$ & 13.8 \\
Percentage of encounters with a prescribed antibiotic & $70 / 509$ & \\
Percentage of encounters with a prescribed injection & & \\
\hline
\end{tabular}

All information on the record were recorded and entered into a personal computer. Information recorded included age, gender, diagnosis and drugs prescribed. Data was analysed to measure drug use indicators using Epi info v 6.06c software.10

The findings of the study are limited by the availability of completeness of information recorded on the patents' case notes. Such missing information may have some influence on the parameters estimated

\section{Results}

A total of 509 records that had complete records out of the 600 records sampled were analysed for drug-use indicators. There were $171(33.6 \%)$ paediatric and $338(66.4 \%)$ adult records. The mean age of the patients seen was 22.6. There were $243(47.7 \%)$ females and 266 (52.3\%) males. The drug use indicators are shown on Table 1 . The average number of drugs was $3.5 \pm 1.4$, with a range of 1 to 9 . Two hundred and sixty-five (52.1\%) patients were prescribed between 1-3 drugs; 224 (44.0\%) received between 4-6 drugs and $20(3.9 \%)$ received 7 or more drugs. The injection-prescribing rate was $13.8 \%, 34$ $(48.6 \%)$ out of the 70 patients who were prescribed injections, received one injection. The antibiotic prescribing rate was $54.8 \%$, majority of the patients (232/279; $83.2 \%$ ) were prescribed one antibiotic.

The indications for antibiotics are shown on Table 2, malaria, acute upper respiratory tract infections and typhoid fever were the top three conditions. Ampicillin + cloxacillin, amoxicillin and ciprofloxacin were the most frequently prescribed antibiotics (Table 3). Combinations of antibiotics distinct from fixed dosage combinations were prescribed frequently. Several of these contained metronidazole and prescribing of bacteriocidal and bacteriostatic agents simultaneously. Table 4 shows that malaria, minor injuries and acute respiratory tract infections were the main indications for injection use. Chloroquine,

\begin{tabular}{|c|c|c|}
\hline Indication & $\mathrm{N}$ & $\%$ \\
\hline Malaria & 69 & 24.7 \\
\hline Acute respiratory tract infection & 61 & 21.9 \\
\hline Typhoid fever & 17 & 6.1 \\
\hline Peptic ulcer & 15 & 5.4 \\
\hline Urinary tract infection & 14 & 5.0 \\
\hline Gastroenteritis & 14 & 5.0 \\
\hline Wounds and injuries & 12 & 4.3 \\
\hline Otitis media & 9 & 3.2 \\
\hline Heart failure & 9 & 3.2 \\
\hline Asthma & 7 & 2.5 \\
\hline Pelvic inflammatory disease & 6 & 2.2 \\
\hline Others $^{*}$ & 46 & 16.5 \\
\hline Total & 279 & 100 \\
\hline
\end{tabular}

dipyrone and promethazine were the most frequently prescribed injections (Table 5). In a number of cases, chloroquine, dipyrone and promethazine injections were prescribed for the same patient.

\section{Discussion}

The drug use indicators obtained at this hospital are in keeping with the trend obtained by other researchers in the country, ${ }^{5-9}$ as the values are similar with those from all levels of care. However, in Ghana, drug-use 


Table 3. Names of Prescribed Antibiotics
\begin{tabular}{lcc}
\hline Indication & $\mathrm{N}$ & $\%$ \\
\hline Ampicillin+cloxacilln & 40 & 14.3 \\
Cotrimoxazole & 38 & 13.6 \\
Amoxycillin & 30 & 10.8 \\
Cephalexin & 30 & 10.8 \\
Ciprofloxacin & 29 & 10.4 \\
Erythromycin & 18 & 6.5 \\
Perfloxacin & 17 & 6.1 \\
Metronidazole & 9 & 3.2 \\
Ampicillin & 9 & 3.2 \\
Other single antibiotics* & 12 & 4.3 \\
Combination of 2 or more antibiotics & 47 & 16.8 \\
Total & 279 & 100 \\
& & \\
*Other single antibiotics include cefuroximc, azithromycin, amoxicillin+ ctavulanic acid
\end{tabular}

\section{Table 4. Indications for Injection Use}

\begin{tabular}{lcl}
\hline Indication & $\mathrm{N}$ & $\%$ \\
\hline Malaria & 38 & 54.3 \\
Wounds and injuries & 10 & 14.3 \\
Acute respiratory tract infection & 9 & 12.8 \\
Asthma & 3 & 4.3 \\
Typhoid fever & 3 & 4.3 \\
Others* & 7 & 10.0 \\
Total & 70 & 100
\end{tabular}

*0thers include peptic ulcer, peptic ulcer, drug allergy.

Table 5. Names of Prescribed Injections

\begin{tabular}{lcc}
\hline Indication & $\mathrm{N}$ & $\%$ \\
\hline Chloroquine & 38 & 30.9 \\
Dipyrone & 26 & 21.1 \\
Promethazine & 18 & 14.6 \\
Tetanus toxoid & 13 & 10.6 \\
Gentamycin & 6 & 4.9 \\
Antitetanus sera & 5 & 4.1 \\
Cefuroxime & 3 & 2.4 \\
Ampicillin + cloxacillin & 3 & 2.4 \\
Others* & 11 & 8.9 \\
Total & 123 & 99.9 \\
& & \\
\hline *0thers include penicillinG, streptomycin, hyoscine, ampicillin+cloxacillin.
\end{tabular}

indicators were reported to be worse at health centres than at hospitals, ${ }^{11}$ The average number of drugs (3.5) is similar to values obtained from teaching hospitals ${ }^{5}$ but lower than values obtained from primary health care centres. ${ }^{7}$ The average number of drugs and antibiotic use obtained at this hospital are comparable to the 3.16 and $50.3 \%$ respectively reported from another secondary health care facility in Lagos.

The use of antibiotics is surprisingly high but comparable to the rates obtained at primary health care centres, ${ }^{6,7,12}$ although these latter facilities are manned by non-doctors unlike in the hospital.
Antibiotics were prescribed for many conditions they were not indicated for and to treat presumed infections especially cough and fevers that could not be diagnosed sufficiently on clinical grounds. This high rate of antibiotic prescribing at this hospital has been documented ${ }^{13}$ and has a number of implications. Firstly, newer and more expensive antibiotics are frequently prescribed which may be unaffordable to most patients and poor compliance in those who may be able to start a course but are unable to finish. Secondly, it also tends to promote antibiotic resistance as the antibiotic resistance pattern at this hospital is becoming similar to that 
reported from a teaching hospital. ${ }^{14}$

The injection use rate is lower the rates from previous studies, ${ }^{6,8}$ though for many of the indications, oral therapy would have sufficed. It may be that the doctors at the hospital are more aware of the hazards of injection therapy and therefore more cautious. The pattern of injection use of giving " 3 in 1" consisting of chloroquine, dipyrone and promethazine observed has been reported from primary care health centres. There is no justification for this treatment modality. ${ }^{7}$ Factors known to influence drug-use indicators such as level of training of the health worker, patient pressure and detailing by pharmaceutical company representatives are also likely to exert the same degree of influence at this hospital. ${ }^{8,13}$

The overall picture of drug use suggests that the indicators at this facility are not yet at the optimal level and need some intervention. Ways of improving the prescribing practices include continuing education on rational drug use, provision of rapid diagnostic tests especially at the side laboratory, increasing doctors awareness about non-drug therapy and improving doctors' communication skills so that they are better at counselling and informing patients about non-drug therapy.

\section{References}

1. Odusanya OO, Bamgbala AO. A community based assessment of a model primary health care centre. Nig Qt J Hosp Med 1999, 9:260-263.

2. World Health Organisation, Geneva, 1987. The rational use of drugs. Report of the Conference of Experts; 1985, 25-29 November. World Health Organisation, Geneva.

3. World Health Organisation, Geneva, 1993 How to investigate drug use in health facilities: selected drug use indicators. World Health Organisation.

4. Hogerzeil HV, Bimo, Ross-Degnan D et al. Field tests for rational drug use in twelve Developing Countries. Lancet 1993,342, 1408-1410.
5. Mabadeje AFB, Akintonwa AA, Ashorobi RB. The value and effects ofimplementing an essential drugs list in the Lagos University Teaching Hospital. Clinical Pharmacology \& Therapeutics 1991, 50:121-124

6. Akinyede AA, Mabadeje AFB, Aliu A. A comparative study of patterns ofprescription of antibiotics in two health centres in Lagos. Journal of the Nigerian Infection Control Association; 2000: 3,20-23

7. Odusanya 00 , Oyediran MA. Rational drug use at primary health care centres in Lagos, Nigeria. Nigerian Quarterly journal of Hospital Medicine 2000:10(1):4-7

8. Ohaju-Obodo JO, Isah AO, Mabadeje AFB. Prescribing pattern ofclinicians in private health institutions in Edo and Delta states of Nigeria. Nig Qt J Hosp Med 1998:8:91-94.

9. Chukwuani CM, Onifade M, Sumonu K. Survey of drug use practicesand antibiotic prescribing pattern at a general hospital in Nigeria. Pharm World Sci 2002, 24:188-95.

10. Dean AD, Dean JA, Burton JH, Dicker RC. Epi Info, version 6: A wordprocessing, database and statistics program for epidemiology on microcomputers, Centres for Disease Control, Atlanta, Georgia, USA, 1994.

11. Bosu WK, Ofori-Adjei D. An audit of prescribing practices in health carefacilities of the Wassa West district of Ghana. West Afr J Med. 2000, 19:298-303 12. Odusanya 0. 0. Antibiotic prescribing at primary health care facilities in Lagos. Journal of the Nigerian Infection Control Association 1999, 2:24-26

13. Odusanya 0. 0. A study of antibiotic prescribing at a General Hospital in Lagos, Nigeria. Nigerian Medical Practitioner 2002, 42:8-11.

14. Odusanya 0. 0. Antibiotic susceptibility of microorganisms at a general hospital in Lagos. Nigeria. Journal of the National Medical Association 2002; 94:994-998. 